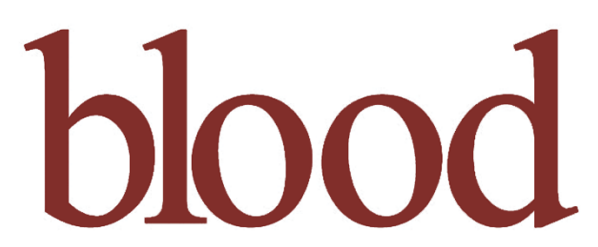

2008 112: 4139-4147

Prepublished online September 4, 2008;

doi:10.1182/blood-2008-02-140715

\title{
WASP confers selective advantage for specific hematopoietic cell populations and serves a unique role in marginal zone B-cell homeostasis and function
}

Lisa S. Westerberg, Miguel A. de la Fuente, Fredrik Wermeling, Hans D. Ochs, Mikael C. I. Karlsson, Scott B. Snapper and Luigi D. Notarangelo

Updated information and services can be found at:

http://bloodjournal.hematologylibrary.org/content/112/10/4139.full.html

Articles on similar topics can be found in the following Blood collections

Immunobiology (5064 articles)

Information about reproducing this article in parts or in its entirety may be found online at:

http://bloodjournal.hematologylibrary.org/site/misc/rights.xhtml\#repub_requests

Information about ordering reprints may be found online at:

http://bloodjournal.hematologylibrary.org/site/misc/rights.xhtml\#reprints

Information about subscriptions and ASH membership may be found online at:

http://bloodjournal.hematologylibrary.org/site/subscriptions/index.xhtml

Blood (print ISSN 0006-4971, online ISSN 1528-0020), is published weekly by the American Society of Hematology, 2021 L St, NW, Suite 900,

Washington DC 20036.

Copyright 2011 by The American Society of Hematology; all rights reserved.

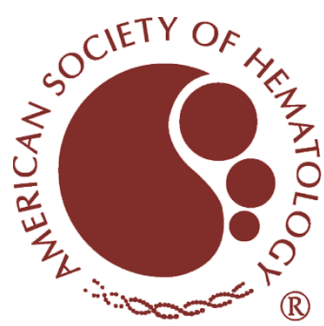




\title{
WASP confers selective advantage for specific hematopoietic cell populations and serves a unique role in marginal zone B-cell homeostasis and function
}

\author{
Lisa S. Westerberg, ${ }^{1,2}$ Miguel A. de la Fuente, ${ }^{3,4}$ Fredrik Wermeling, ${ }^{5}$ Hans D. Ochs, ${ }^{6}$ Mikael C. I. Karlsson, ${ }^{5}$ \\ ${ }^{*}$ Scott B. Snapper, ${ }^{1,2}$ and *Luigi D. Notarangelo ${ }^{3,4}$ \\ ${ }^{1}$ Gastrointestinal Unit and the Center for the Study of Inflammatory Bowel Diseases, Massachusetts General Hospital, Boston; ${ }^{2}$ Department of Medicine, \\ Harvard Medical School, Boston, MA; ${ }^{3}$ Division of Immunology, Children's Hospital, Boston, MA; ${ }^{4}$ Department of Pediatrics, Harvard Medical School, Boston, \\ MA; ${ }^{5}$ Unit of Clinical Allergy Research, Department of Medicine, Karolinska Institute, Stockholm, Sweden; and ${ }^{6}$ Department of Pediatrics, University of \\ Washington School of Medicine, Seattle
}

\begin{abstract}
Development of hematopoietic cells depends on a dynamic actin cytoskeleton. Here we demonstrate that expression of the cytoskeletal regulator WASP, mutated in the Wiskott-Aldrich syndrome, provides selective advantage for the development of naturally occurring regulatory $T$ cells, natural killer $\mathrm{T}$ cells, $\mathrm{CD}^{+}$and $\mathrm{CD}^{+}{ }^{+} \mathrm{T}$ lymphocytes, marginal zone (MZ) B cells, MZ macrophages, and platelets. To define the relative contribution of MZ B cells and MZ macro-
\end{abstract}

phages for MZ development, we generated wild-type and WASP-deficient bone marrow chimeric mice, with full restoration of the MZ. However, even in the presence of MZ macrophages, only $10 \%$ of MZ B cells were of WASP-deficient origin. We show that WASP-deficient MZ B cells hyperproliferate in vivo and fail to respond to sphingosine-1phosphate, a crucial chemoattractant for MZ B-cell positioning. Abnormalities of the MZ compartment in WASP $^{-/-}$mice lead to aber- rant uptake of Staphylococcus aureus and to a reduced immune response to TNPFicoll. Moreover, WASP-deficient mice have increased levels of "natural" IgM antibodies. Our findings reveal that WASP regulates both development and function of hematopoietic cells. We demonstrate that WASP deficiency leads to an aberrant MZ that may affect responses to blood-borne pathogens and peripheral B-cell tolerance. (Blood. 2008; 112:4139-4147)

\section{Introduction}

The Wiskott-Aldrich syndrome (WAS) is a severe immunodeficiency characterized by a complex phenotype and an increased mortality resulting from hemorrhage, severe infections, and malignancy. Defective expression of WAS protein (WASP) leads to multiple abnormalities in different hematopoietic cells in patients with WAS and WASP-deficient mice. ${ }^{1}$ Hematopoietic stem cell transplantation (HSCT) represents an effective treatment strategy for severe WAS patients ${ }^{2,3}$; however, the degree of donor engraftment in various hematopoietic compartments is an important determination of successful treatment. ${ }^{4}$ In severe cases, where suitable donors are unavailable, gene therapy is being considered as an alternative treatment for WAS. ${ }^{5,6}$ However, the role of WASP in the development of hematopoietic cells remains largely unknown. A detailed analysis of the possible advantage for WASP-expressing cells over WASP-negative cells in a competitive setting should provide insight into which lineages are more probable to be corrected by gene therapy.

The splenic marginal zone (MZ) contains specialized B cells and highly phagocytic MZ macrophages (MZMs) that create a first line of defense to blood-borne pathogens. ${ }^{7}$ Reduced number of $\mathrm{MZ}$ $B$ cells of WAS patients and WASP-deficient mice may contribute to the weak immune response to bacteria. ${ }^{8,9}$ The natural MZ B-cell repertoire has a low self-reactivity that enables them to rapidly respond to blood-borne antigens. ${ }^{10} \mathrm{MZ}$ B-cell development from transitional-2-marginal zone precursor (T2-MZP) cells has been suggested to depend on Notch2-activated gene transcription and on
B-cell receptor (BCR) signaling strength. ${ }^{11,12}$ Furthermore, MZ B-cell positioning is critically dependent on interactions with ICAM-1 and VCAM-1 and responsiveness to sphingosine-1phosphate (S1P). ${ }^{13,14} \mathrm{MZ}$ B-cell retention may involve signals from MZMs because depletion of MZMs leads to a severe reduction of MZ B cells. ${ }^{15}$ Accordingly, MZ B-cell development, positioning, and function depend on both B-cell intrinsic activity and on the presence of MZMs.

By analyzing WASP-expressing cells in the competitive setting of $\mathrm{WASP}^{+/-}$mice, we show that WASP is essential for development of nTregs, NKT cells, and to a lesser extent for platelets but is dispensable for development of myeloid cells. In addition, we show that WASP directly regulates development, positioning, and function of MZ B cells and MZMs.

\section{Methods}

Mouse strains, mixed bone marrow chimeras, and bone marrow cultures

Wild-type (WT) Balb/c and C57BL/6 mice were purchased from Charles River Laboratories (Wilmington, MA). WASP ${ }^{+/-}$and $\mathrm{WASP}^{-/-}$mice ${ }^{16}$ on Balb/c background (backcrossed 8 generations) were used for all experiments except for those that required an alternative background as follows. For bone marrow (BM) chimeras, WT C57BL/6 mice expressing CD45.1 were purchased from The Jackson Laboratory (Bar Harbor, ME) and used
Submitted February 25, 2008; accepted July 23, 2008. Prepublished online as Blood First Edition paper, September 4, 2008; DOI 10.1182/blood-2008-02-140715.

*S.B.S. and L.D.N. contributed equally to this study.

An Inside Blood analysis of this article appears at the front of this issue.
The online version of this article contains a data supplement.

The publication costs of this article were defrayed in part by page charge payment. Therefore, and solely to indicate this fact, this article is hereby marked "advertisement" in accordance with 18 USC section 1734.

(C) 2008 by The American Society of Hematology 
together with $\mathrm{WASP}^{-/-} \mathrm{C} 57 \mathrm{BL} / 6$ mice backcrossed 4 generations (expressing CD45.2). WASP $P^{-1-}$ C57BL/6 mice were used for immunizations because TNP-Ficoll induces an efficient immune response in WT C57BL/6 mice. WASP $P^{-1-} / b t k^{\text {xid }}$ double-deficient mice were generated by breeding $W A S P^{-/-} 129 \mathrm{~Sv}$ mice with $b t k^{\mathrm{xid}}$ mice (The Jackson Laboratory). For generation of mixed BM chimeras, $10^{7}$ total BM cells containing WT and $W A S P^{-1-}$ were transplanted via intravenous injection into lethally irradiated $(10.5 \mathrm{~Gy}) \mathrm{WASP}^{-1-}$ recipient animals. BM cells $\left(10^{6} / \mathrm{mL}\right)$ were cultured for 7 days in RPMI medium 1640 with $2 \mathrm{mM}$ of L-glutamine/ $1 \mathrm{mM}$ of sodium pyruvate $/ 100$ units $/ \mathrm{mL}$ of penicillin/streptomycin/50 $\mu \mathrm{M}$ of 2-mercapthoethanol/10\% fetal calf serum supplemented with recombinant macrophage colony-stimulating factor (M-CSF) for macrophage cultures and granulocyte-macrophage colony-stimulating factor (GM-CSF) for dendritic cell (DC) cultures (20 $\mu \mathrm{g} / \mathrm{mL}$, PeproTech, Rocky Hill, NJ). Mice were housed at Massachusetts General Hospital under specific pathogenfree conditions. Animal experiments were carried out after approval and in accordance with guidelines from the Subcommittee on Research Animal Care of Massachusetts General Hospital.

\section{Flow cytometry and immunohistochemistry}

For flow cytometry, single-cell suspensions in phosphate-buffered saline and $5 \%$ fetal calf serum and $0.1 \%$ sodium azide were labeled with antimouse antibodies (Table 1). Antimouse antibodies used included: Sca-1, c-kit, CD11b, CD11c, Gr-1, B220, CD43, IgM, IgD, CD25, CD44, CD4, CD8, CD21, CD23, CD24, CD41 and CD61, CD93, IgD, TNP, streptavidin conjugates (BD Biosciences, San Jose, CA), IgM, CD21, CD23, CD45.1, CD45.2, Foxp3, Dx5 (eBioscience, San Diego, CA), peanut agglutinin (PNA; Vector Laboratories, Burlingame, CA), and fluorescently labeled antirat and antirabbit IgG secondary antibodies (Jackson Laboratory). Phycoerythrin-labeled CD1d tetramers were a kind gift from Svend Rietdijk and Cox Terhorst (Harvard Medical School, Boston, MA). Foxp3 antibody-staining reagents were used according to the eBioscience protocol. Purified polyclonal rabbit anti-WASP antibody was generated as described, ${ }^{17}$ and staining was performed with Fix and Perm permeabilization kit (Invitrogen, Carlsbad, CA). Data were acquired on a FACSCalibur cytometer (BD Biosciences) or on a BD LSR II Flow Cytometry and analyzed using FlowJo for Mac version 8.2 (Tree Star, Ashland, OR). For immunohistochemistry, 4- $\mu \mathrm{m}$ cryostat spleen sections were fixed in icecold acetone, labeled with antimouse antibodies for CD1d, B220, F4/80, CD11b, CD11c, TNP (BD Biosciences), Sialoadhesin, SIGN-R1, MARCO, and MOMA-1 (Serotec, Raleigh, NC) in phosphate-buffered saline with 5\% fetal calf serum and $0.3 \%$ Tween 20, and mounted in Mowiol (Calbiochem, San Diego, CA). For Staphylococcus aureus uptake in the spleen, $25 \mu \mathrm{g}$ of fluorescein isothiocyanate (FITC)-labeled organisms (Invitrogen) were injected intravenously and spleens examined by immunohistochemistry 30 minutes after injection.

Slides were viewed with an Olympus Provis AX70 research system microscope (Olympus Optical, Tokyo, Japan) using an UplanApo or UplanFl lens at $10 \times / 0.40 \mathrm{Phl} \propto / 0.17$ and $20 \times / 0.50 \mathrm{Phl} \propto / 0.17$, respectively, and Mowiol medium (Calbiochem, San Diego, CA). Images were acquired using a UPHOTO Universal Photo System camera (Olympus) model U-CMAD-2 and were processed with MagnaFire 2.1c (Optronics, Goleta, CA) and Adobe Photoshop CS version 8.0 (Adobe Systems, San Jose, CA).

\section{BrdU incorporation, cell death, adhesion, and chemotaxis}

For continuous in vivo bromodeoxyuridine (BrdU) labeling, mice were fed BrdU (1 mg/mL from Sigma-Aldrich, St Louis, MO) in 10\% sucrosesupplemented drinking water for 6 days and thereafter with normal drinking water for another 6 days. BrdU incorporation in spleen cells at days 3, 6, 9, and 14 was determined using the FITC BrdU flow kit (BD Biosciences). For cell death analysis, splenocytes stained with antibodies to CD21 and CD23 were labeled with FITC-conjugated annexin V and 7-amino-actinomycin D (7-AAD; BD Biosciences). Dead cells were defined as 7-AAD ${ }^{+}$cells and apoptotic cells as 7-AAD ${ }^{-}$annexin $\mathrm{V}^{+}$. For adhesion to intercellular adhesion molecule-1 (ICAM-1) and vascular cell adhesion molecule 1 (VCAM-1; R\&D Systems, Minneapolis, MN), splenocytes were allowed to adhere to ligand-coated microtiter plates for 2 hours. ${ }^{13}$ Adherent cells were
Table 1. Markers used to define HPC and lineage cells

\begin{tabular}{|c|c|}
\hline Hematopoietic lineage cells & Marker \\
\hline \multicolumn{2}{|l|}{ T-cell lineage } \\
\hline \multicolumn{2}{|l|}{ THY } \\
\hline DN1 & $\mathrm{CD}_{25}^{-} \mathrm{CD} 44^{+} \mathrm{Lin}^{-}$ \\
\hline DN2 & $\mathrm{CD}_{25}{ }^{+} \mathrm{CD} 44^{+} \mathrm{Lin}^{-}$ \\
\hline DN3 & $\mathrm{CD}_{25}{ }^{\mathrm{C}} \mathrm{CD} 44^{-} \mathrm{Lin}^{-}$ \\
\hline DN4 & $\mathrm{CD}^{-} 5^{-} \mathrm{CD} 44^{-} \mathrm{Lin}^{-}$ \\
\hline DP & $\mathrm{CD}^{+} \mathrm{CD}^{+}$ \\
\hline \multicolumn{2}{|l|}{ THY/SPL } \\
\hline CD4 SP & $\mathrm{CD} 4^{+} \mathrm{TCR}^{\mathrm{hi}}$ \\
\hline CD8 SP & $\mathrm{CD}^{+} \mathrm{TCR}^{\mathrm{hi}}$ \\
\hline nTreg & $\mathrm{Foxp}^{+} \mathrm{CD}^{+}{ }^{+} \mathrm{CD} 25^{+}$ \\
\hline NKT & $\mathrm{TCR}^{+} \mathrm{CD}_{1 \mathrm{~d}^{+}}$ \\
\hline \multicolumn{2}{|l|}{ B-cell lineage } \\
\hline \multicolumn{2}{|l|}{ BM } \\
\hline $\mathrm{HPC}$ & Sca1 ${ }^{+}$ckit $^{+}$Lin $^{-\star}$ \\
\hline FrA & $\mathrm{CD}_{4} 3^{+} \mathrm{B} 220^{10} \mathrm{CD}_{24}^{-}$ \\
\hline $\mathrm{FrB}+\mathrm{C}$ & $\mathrm{CD}_{43}{ }^{+} \mathrm{B} 220^{10} \mathrm{CD}^{2} 4^{+}$ \\
\hline FrD & $\mathrm{CD}_{43}{ }^{-} \mathrm{B}^{2} 2 \mathrm{O}^{+} \mathrm{IgM}^{-} \mathrm{IgD}^{-} \mathrm{CD} 93+$ \\
\hline FrE & $\mathrm{CD}_{43}{ }^{-} \mathrm{B}_{220^{+}} \mathrm{IgM}^{+} \operatorname{lgD}^{-} \mathrm{CD} 93+$ \\
\hline $\mathrm{FrF}$ & $\mathrm{CD}_{4} 3^{-} \mathrm{B} 20^{+} \lg \mathrm{M}^{+} \lg \mathrm{D}^{+} \mathrm{CD} 93-$ \\
\hline \multicolumn{2}{|l|}{ SPL } \\
\hline $\mathrm{T} 1$ & $\mathrm{CD}^{2} 3^{-} \mathrm{IgM}^{+} \mathrm{CD} 24^{+} \mathrm{CD} 21^{-10}$ \\
\hline T2-FO & $\mathrm{CD}_{23}{ }^{\mathrm{C}} \mathrm{CD} 24^{+} \mathrm{CD}_{21}{ }^{10}$ \\
\hline FO & $\mathrm{CD}_{23}{ }^{+} \operatorname{lgM}^{\text {int }} \mathrm{CD} 24^{10} \mathrm{CD} 21^{+}$ \\
\hline T2-MZP & $\mathrm{CD}_{23}{ }^{+} \operatorname{IgM}^{\mathrm{hi}} \mathrm{CD} 24^{+} \mathrm{CD} 21^{\mathrm{hi}}$ \\
\hline $\mathrm{MZ}$ & $\mathrm{CD}_{23}^{-} \operatorname{lgM}^{+} \mathrm{CD}_{24}{ }^{+} \mathrm{CD} 21^{\mathrm{hi}}$ \\
\hline \multicolumn{2}{|l|}{ PT } \\
\hline B1a & CD19hi $\mathrm{CD}^{+} \mathrm{B}^{2} 20^{10}$ \\
\hline B2 & CD19lo CD5- B220hi \\
\hline \multicolumn{2}{|l|}{ PPs } \\
\hline PNA- & $\mathrm{B}_{220^{+}} \mathrm{CD}_{19}{ }^{+} \mathrm{PNA}^{+}$ \\
\hline $\mathrm{PNA}+$ & $\mathrm{B}_{220}+\mathrm{CD}_{19}+\mathrm{PNA}^{-}$ \\
\hline \multicolumn{2}{|l|}{ Myeloid cells } \\
\hline \multicolumn{2}{|l|}{$\mathrm{BM} / \mathrm{SPL}$} \\
\hline Imm N & $\mathrm{Gr}^{10} \mathrm{CD} 11 \mathrm{~b}^{+}$ \\
\hline Mat $\mathrm{N}$ & $\mathrm{Gr}^{\mathrm{hi}} \mathrm{CD} 11 \mathrm{~b}^{+}$ \\
\hline \multicolumn{2}{|l|}{ SPL/culture } \\
\hline NK & $\mathrm{D} \times 5^{+} \mathrm{TCR}^{-}$ \\
\hline DC & $\mathrm{CD}_{11 \mathrm{~b}^{+}} \mathrm{CD}_{11 \mathrm{c}^{+}}$ \\
\hline $\mathrm{Mo} / \mathrm{Ma}$ & $\mathrm{CD} 11 \mathrm{~b}^{+} \mathrm{CD} 11 \mathrm{c}^{-}$ \\
\hline \multicolumn{2}{|l|}{ PB } \\
\hline Platelets & $\mathrm{CD} 41^{+} \mathrm{CD} 61^{+}$ \\
\hline
\end{tabular}

$\mathrm{B}$ indicates $\mathrm{B}$ cell; $\mathrm{B} 1 / \mathrm{B} 2$, peritoneal $\mathrm{B}$ cells; BM, bone marrow; culture, bone marrow cells cultured for 7 days with M-CSF or GM-CSF; DC, dendritic cell; DN, CD4CD8 double-negative; $\mathrm{DP}, \mathrm{CD} 4 \mathrm{CD} 8$ double-positive; FO, follicular; $\mathrm{Fr}$, fraction; HPC, hematopoietic progenitor cells; Mo/Ma, monocyte/macrophage; MZ, marginal zone; N, neutrophil; NK, natural killer cell; NKT, NK T cell; nTregs, naturally occurring T cells; PB, peripheral blood; PNA, peanut agglutinin; PPs, Peyer's patches; PT, peritoneum; SP, CD4 or CD8 single-positive; SPL, spleen; T1, transitional $1 \mathrm{~B}$ cell; T2 transitional 2 B cell; T2-FO, transitional 2 follicular precursor B cell; T2-MZP, transitional 2 marginal zone precursor B cell; and THY, thymus.

${ }^{*} \mathrm{Lin}^{-}$: CD11b, CD11c, Gr-1, CD4, CD8, B220.

released by incubating for 15 minutes on ice in RPMI with $5 \mathrm{mM}$ of ethylenediaminetetraacetic acid. Adhesion was calculated as a percentage of "input" samples that had been incubated in parallel on bovine serum albumin-coated wells. For in vitro migratory response, splenocytes $\left(2 \times 10^{5}\right)$ were allowed to migrate to S1P (Sigma-Aldrich) for 3 hours in Transwell chemotaxis chambers (5 $\mu \mathrm{m}$; Corning Life Sciences, Acton, MA).

\section{Cell sorting and real-time polymerase chain reaction}

Splenic B cells were sorted on a FACSVantage (BD Biosciences). Extraction of RNA was performed using Trizol (Invitrogen) and cDNA generated using iScript cDNA Synthesis kit (Bio-Rad, Hercules, CA). Real-time quantitative polymerase chain reaction (PCR) was performed in 
the DNA Engine Opticon 2 system (MJ Research, Watertown, MA) using the iQTMSYBR Green super mix (Bio-Rad). The thermal cycling conditions were 4 minutes at $95^{\circ} \mathrm{C}$, followed by 50 cycles at $94^{\circ} \mathrm{C}$ for 15 seconds, $62^{\circ} \mathrm{C}$ for 15 seconds, and $72^{\circ} \mathrm{C}$ for 45 seconds. The primer sequences were $\mathrm{S}_{1} \mathrm{P}_{1} 5^{\prime}$-GTGTAGACCCAGAGTCCTGCG-3' (forward) and 3' - AGCTTTTCCTTGGCTGGAGAG-5' (reverse), S1P $35^{\prime}$ '-GGAGCCCCTAGACGGGAGT-3' (forward) and 3'-CCGACTGCGGGAAGAGTGT-5' (reverse), and hypoxanthine phosphoribosyltransferase (HPRT) 5'-AGGTTGCAAGCTTGCTGGT-3' (forward) and $3^{\prime}$-TGAAGTACTCATTATAGTCAAGGGCA-5' (reverse). The test sample $C_{T}$ was calculated by subtracting the calibrator gene HPRT $C_{T}$ value from the test sample $C_{T}$ value and thus represented the relative quantity of the target mRNA normalized to HPRT mRNA. The mRNA content of test sample in WT follicular B cells was defined as 1 arbitrary unit.

\section{TNP-Ficoll immunization}

For TI-2 antigen responses, age- and sex-matched C57BL/6 mice were injected intravenously with 2,4,6-trinitrophenol (TNP)-Ficoll (Biosearch Technologies, Novato CA). Uptake of TNP-Ficoll in the MZ and by MZ B cells was examined 30 minutes and 3 hours after injection, and anti-TNP IgM and IgG3 antibody titers were measured by enzyme-linked immunosorbent assay at day 7 . The samples were run in triplicates and corrected for background binding.

\section{Statistics}

Data are expressed as mean plus or minus SD where indicated. Statistical significance between groups was assessed by 2-tailed Student $t$ test and analysis of variance. Differences were considered significant when $P$ was less than .05 .

\section{Results}

\section{Selective advantage for WASP-expressing cells in WASP $^{+/-}$ mice}

Prior studies have suggested that WASP expression confers developmental, proliferative, and/or functional advantage to various hematopoietic populations. ${ }^{1,18-20}$ Using the natural competitive setting of $\mathrm{WASP}^{+/-}$ mice on Balb/c background, we sought to determine the proportion of cells expressing WASP in different hematopoietic cell lineages (Table 1). Preliminary analysis of $W A S P^{+/-}$mice revealed that it was difficult to appreciate the contribution of WASP $^{-}$cells in those mice that had a high proportion of $\mathrm{WASP}^{+}$hematopoietic progenitor cells (HPCs). Accordingly, we included in our study those $W_{A S P^{+/-}}$mice that expressed less than $65 \% \mathrm{WASP}^{+}$HPCs $(43 \% \pm 13 \%, \mathrm{n}=13$ mice $)$.

In the thymus, no advantage for WASP-expressing cells was observed during development of double-negative (DN) and doublepositive cells (DP) compared with the proportion of WASP-expressing cells in BM HPCs (HPCs: $43 \% \pm 13 \%$; DN: $52 \% \pm 17 \%$; DP: $62 \% \pm 16 \%, P=$ not significant, Figure 1A). The percentage of $\mathrm{WASP}^{+}$cells was significantly higher among single-positive (SP) CD4 and $\mathrm{CD} 8$ cells $\left(\mathrm{CD} 4{ }^{+} \mathrm{SP}: 65 \% \pm 15 \% ; \mathrm{CD}^{+} \mathrm{SP}: 64 \% \pm 16 \%, P<.01\right.$, Figure 1A). Remarkably, the majority of nTregs and NKT cells in the thymus expressed WASP $(84 \% \pm 12 \%$ and $83 \% \pm 11 \%$, respectively, $P<.005$, Figure 1A). An even greater selective advantage for WASPexpressing $\mathrm{SP} \mathrm{CD}^{+}$and $\mathrm{CD}^{+} \mathrm{T}$ cells, nTregs and NKT cells was observed in the spleen $\left(\mathrm{CD}^{+}: 72 \% \pm 9 \%\right.$; $\mathrm{CD}^{+}: 74 \% \pm 9 \%$; nTregs: $93 \% \pm 4 \%$; NKT: $86 \% \pm 8 \%$, respectively, $P<.005$, Figure $1 \mathrm{~A})$. In keeping with a strong advantage for WASP-expressing nTregs (as we previously have published $)^{21}$ and NKT cells in $W_{A S P^{+/-}}$mice, the absolute number of these cells was reduced in $\mathrm{WASP}^{-/-}$mice compared with control mice (NKT cells in thymus: WT $149 \pm 20 \times 10^{3}$ and WASP $^{-1-} 111 \pm 31 \times 10^{3}, \mathrm{n}=4, \quad P<.005 ;$ and spleen WT $131 \pm 3 \times 10^{3}$ and $\left.W A S P^{-/-} 89 \pm 8 \times 10^{3}, \mathrm{n}=4, P<.005\right)$.
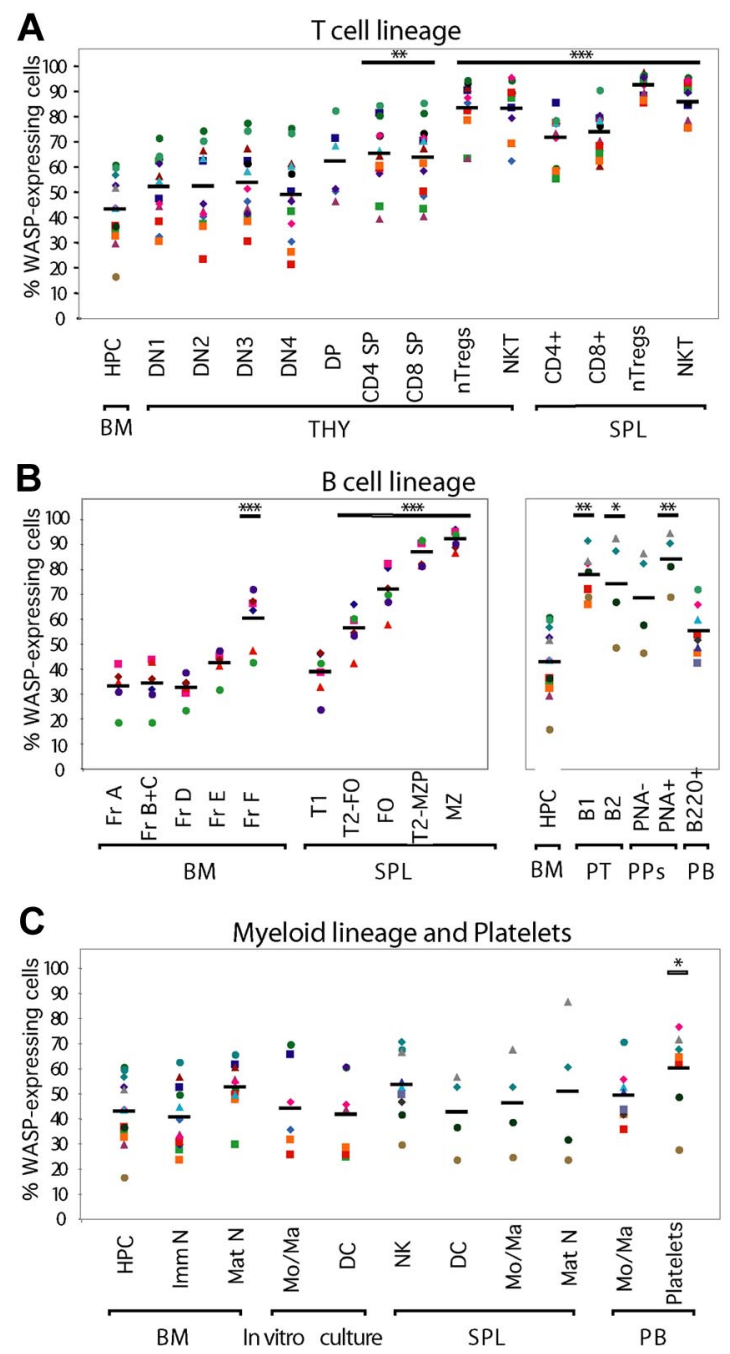

Figure 1. Selective advantage of WASP-expressing cells in WASP+/- mice. HPCs and hematopoietic lineage cells were defined by surface and intracellular markers, labeled with anti-WASP antibodies, and analyzed by flow cytometry. Percentage of WASP-expressing cells is indicated in (A) the T-cell lineage, $(B)$ the $\mathrm{B}$-cell lineage, and $(\mathrm{C})$ the myeloid lineage. Each color represents data from one mouse. Black bar represents the mean of the group. B indicates B cell; B1/B2, peritoneal B cells; BM, bone marrow; DC, dendritic cell; DN, CD4CD8 doublenegative; DP, CD4CD8 double-positive; FO, follicular; Fr, fraction, HPC, hematopoietic progenitor cells; Mo/Ma, monocyte/macrophage; $\mathrm{MZ}$, marginal zone; $\mathrm{N}$, neutrophil; NK, natural killer cell; NKT, NK T cell; nTregs, naturally occurring T cells; PB, peripheral blood; PNA, peanut agglutinin; PPs, Peyer patches; PT, peritoneum; SP, CD4 or CD8 single-positive; SPL, spleen; T1/T2, transitional 1/2 B cell; T2-FO, transitional 2 follicular precursor $\mathrm{B}$ cell; T2-MZP, transitional 2 marginal zone precursor B cell; THY, thymus. In vitro cultured Mo/Ma and DCs were obtained by culturing BM cells in vitro for 7 days with M-CSF and GM-CSF, respectively. $P$ values use a $t$ test to compare percentage of WASP-expressing cells in the T-cell, B-cell (right panel), and myeloid lineages to that of HPCs and for the B-cell lineage (left panel) to that of $\operatorname{Fr} A$ (pro-B) cells: ${ }^{\star} P<.05,{ }^{* *} P<.01,{ }^{* * *} P<.005$.

In the BM, we used the Hardy classification ${ }^{22}$ for central B-cell development and included CD93 to distinguish immature and mature B cells (Figures 1B left panel and S1A, available on the Blood website; see the Supplemental Materials link at the top of the online article). There was no advantage for WASP-expressing cells during the pro-B cell to immature B cell stages (Hardy fraction [Fr] A: $33 \% \pm 8 \%$ WASP-positive; Fr B + C: $34 \% \pm 9 \%$; Fr D: $33 \% \pm 5 \%$; Fr E: $42 \% \pm 5 \% ; P=$ not significant, Figure 1B left panel). In contrast, WASP-expressing recirculating $\operatorname{IgD}^{+} \mathrm{B}$ cells (Fr F) showed selective advantage over WASP $^{-}$cells compared with pro-B cells (Fr A: $33 \% \pm 8 \%$; Fr F: $60 \% \pm 12 \%, P<.005$, Figure 1B left panel). In the spleen, compared with pro-B cells (Fr 
A), WASP-expressing T1 B cells showed no selective advantage over WASP $^{-}$cells (T1: $39 \% \pm 9 \%, P=$ not significant, Figures 1B left panel, S1). In contrast, all other B-cell populations showed advantage for WASP-expressing cells (T2-FO: $57 \% \pm 8 \%$; FO: $72 \% \pm 9 \%$; T2-MZP: $87 \% \pm 5 \%$; MZ: $92 \% \pm 4 \%, P<.005$, Figures 1B left panel, S1). This advantage was particularly striking among MZ B cells where at least $88 \%$ of cells expressed WASP. A higher proportion of WASP-expressing cells was also found among B1 and B2 peritoneal B cells (B1: 77\% $\pm 9 \%, P<.01$; B2 cells: $74 \% \pm 20 \%, P<.05$, Figure $1 \mathrm{~B}$ right panel). To define a possible advantage for WASP-expressing cells in the germinal center (GC) reaction, we analyzed expression of WASP and of PNA, a marker of GC B cells, in Peyer patches, and found that the proportion of WASP $^{+} \mathrm{B}$ cells was consistently higher among $\mathrm{PNA}^{+}$than among PNA $^{-}$cells $(84 \% \pm 11 \%$ vs $68 \% \pm 19 \%, P<.01$, Figure $1 \mathrm{~B}$ right panel). To address the GC response on antigen challenge, $\mathrm{WASP}^{+/-}$ mice were immunized with sheep red blood cells. The proportion of WASP-expressing cells at day 6 after immunization was significantly higher among $\mathrm{PNA}^{+}$compared with $\mathrm{PNA}^{-}$cells $(82 \% \pm 6 \%$ vs $60 \% \pm 8 \%, P<.005$, Figure S2), suggesting that expression of WASP may be required for optimal GC responses.

Consistent with recent findings, ${ }^{18}$ WASP expression did not impart a selective advantage in the myeloid compartment. In particular, the percentage of WASP-expressing cells among BM immature and mature neutrophils, splenic DCs, macrophages, neutrophils, and NK cells were similar to that found among BM HPCs (Figure 1C). Importantly, however, a higher proportion of circulating platelets were found to be $\mathrm{WASP}^{+}$compared with $\mathrm{BM}$ HPCs $(60 \% \pm 17 \%$ vs $43 \% \pm 13 \%, P<.05)$. Because a previous study suggested an advantage for WASP-expressing myeloid cells using in vitro colony forming assays, ${ }^{20}$ we also analyzed the proportion of WASP-expressing $\mathrm{BM} \mathrm{WASP}^{+/-}$cells cultured in vitro for 7 days with M-CSF to generate macrophages or with GM-CSF to generate myeloid DCs and found no evidence for outgrowth of WASP-expressing cells (Figure 1C).

\section{Abnormalities of MZ B cells and MZMs in WASP ${ }^{-/-}$mice}

WAS patients and WASP ${ }^{-/-}$mice have a reduced number of MZ B cells. ${ }^{89}$ We have previously shown that MZ B-cell positioning is dependent on MZMs. ${ }^{15}$ To test the possibility that the reduced number of $\mathrm{MZ} \mathrm{B}$ cells in $W A S P^{-/-}$mice could be caused by abnormalities in MZMs or other MZ resident cells (schematically depicted in Figure 2A), we examined spleen sections from WT and

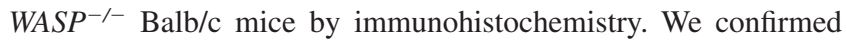
that the number of MZ B cells defined by CD1d and B220 expression was markedly decreased in $\mathrm{WASP}^{-1-}$ mice (Figure $2 \mathrm{~B}$ arrowheads). Positioning of metallophilic (MOMA- $1^{+}$sialoadhe$\sin ^{+}$; Figure $\left.2 \mathrm{~B}\right)$, red pulp $\left(\mathrm{F} 4 / 80^{+}\right)$, and $\mathrm{CD} 11 \mathrm{~b}^{+}$macrophages, as well as CD11 $\mathrm{c}^{+} \mathrm{CD} 11 \mathrm{~b}^{-}$DCs (Figure 2C), was similar in WT and $W A S P^{-/-}$mice. In contrast, MZMs, defined by MARCO and SIGN-R1 receptor expression, were virtually absent in $W A S P^{-/-}$ $\mathrm{Balb} / \mathrm{c}$ mice (Figure 2D arrows) and reduced as well in $W A S P^{-/-}$ C57BL/6 mice (Figure S3).

To investigate the functional consequences of these abnormalities in vivo, we injected WT and WASP ${ }^{-/-}$mice intravenously with FITC-labeled $S$ aureus and examined bacterial uptake in the spleen. As previously described, ${ }^{15} S$ aureus were captured by MZMs, but not by $\mathrm{MOMA}^{+}$metallophilic macrophages in WT mice (Figure $2 \mathrm{E})$. However, uptake of $S$ aureus was impaired in $W A S P^{-{ }^{-}}$mice, and aberrant colocalization of $S$ aureus with metallophilic macrophages was observed (Figure 2E).

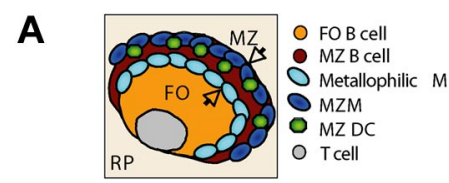

${ }^{\text {BT }}$
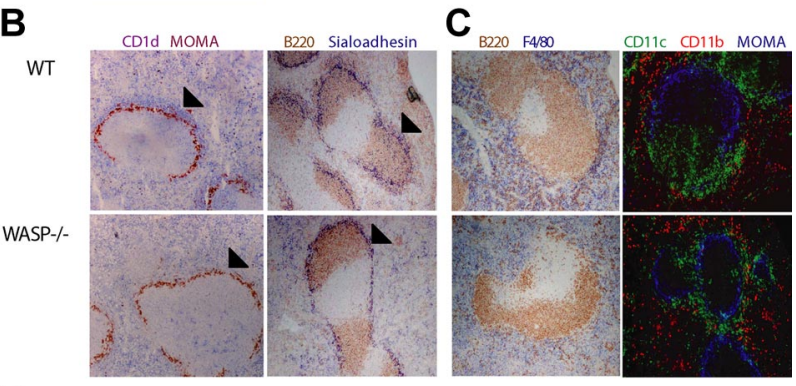

D

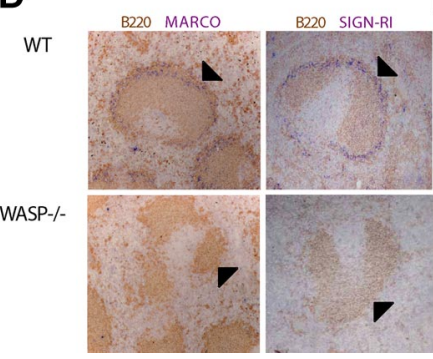

$\mathbf{E}$

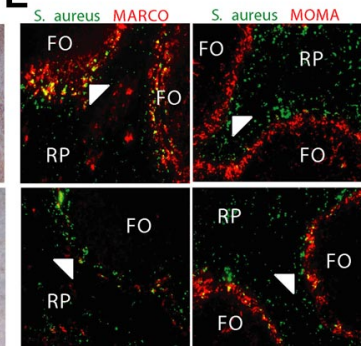

Figure 2. MZ B cells and MZMs are reduced, and $S$ aureus uptake aberrant in WASP-deficient mice. Immunohistochemistry of spleen sections from WT and $W A S P^{-1-}$ mice. (A) Schematic representation of a B-cell follicle and the $\mathrm{MZ}$ in the spleen. Black arrows indicate the MZ. (B) Reduced number of $M Z B$ cells (CD1d ${ }^{+}$

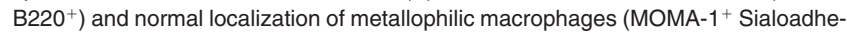
$\left.\mathrm{sin}^{+}\right)$in $\mathrm{WASP}^{-/-}$spleens relative to WT spleens. Black arrowhead represents the $\mathrm{MZ}$. (C) Normal localization of red pulp macrophages $\left(\mathrm{F} 4 / 80^{+}\right), \mathrm{CD} 11 \mathrm{~b}^{+}$macrophages, and DCs $\left(\mathrm{CD} 11 \mathrm{c}^{+}\right)$. (D) Reduced number of MZMs $\left(\mathrm{MARCO}^{+} \mathrm{SIGN}-\mathrm{R} 1^{+}\right)$in $W A S P^{-/-}$spleens compared with WT spleens. Black arrow represents MZMs in the $M Z$. (E) Localization of $S$ aureus 30 minutes after intravenous injection. Note that $S$ aureus almost exclusively colocalize with $\mathrm{MARCO}^{+} \mathrm{MZ}$ macrophages in WT mice, whereas $W A S P^{-1-}$ mice show aberrant localization of $S$ aureus. White arrowhead represents the $M Z$. FO indicates $B$-cell follicle; $M Z$, marginal zone; RP, red pulp. Original magnifications: panels $B$ to $D, \times 10 ; D, \times 20$.

\section{WASP-deficient MZ B cells are reduced independently of the presence of MZMs}

Because MZMs are important for MZ B-cell retention, ${ }^{15}$ we sought to determine whether the loss of MZ B cells is caused by the lack of MZMs in $W A S P^{-/-}$mice. We established mixed BM chimeras of WT (expressing CD45.1) and WASP ${ }^{-/-}$(CD45.2) BM cells. Lethally irradiated $W A S P^{-/}$mice were injected with WT or $W A S P^{-/-}$BM cells in a 1:3 ratio and analyzed 9 to 13 weeks after transplantation (schematized in Figure 3A). As a control, recipient mice received cells from WT or from $\mathrm{WASP}^{-/-}$mice only (Figure $3 \mathrm{~B}$ left and center panels). In the BM of chimeric mice, we found that the proportion of $\mathrm{WASP}^{+}$and $\mathrm{WASP}^{-}$cells among pro/pre-B cells was in a $1: 3$ ratio $\left(23 \% \pm 5 \% \mathrm{WASP}^{+}\right.$cells, $\mathrm{n}=7$ mice $)$, supporting our data that WASP-deficient progenitor cells are not impaired in their ability to migrate to, and repopulate, the BM. Reconstitution of the MZ, and the proportion of MZ B cells, was similar in the chimeric mice and in mice that received BM cells from WT mice (Figure 3B,C). In contrast, mice that received WASP-deficient BM cells alone had a markedly reduced proportion of MZ B cells and MZMs (Figure 3B,C). We next evaluated the origin of splenic $B$ cells in the chimeric animals and found that only $10 \%$ of the MZ B cells were of WASP-deficient origin (Figure 3C). This contrasts with the higher proportion of $\mathrm{WASP}^{-}$cells in $\mathrm{T} 1$, FO, and T2-MZP cells (Figures 3C, 4A). Taken together, these 
Figure 3. WASP-deficient MZ B cells are reduced in numbe independent of MZMs. (A) Schematic representation of generation of BM chimeric mice. WT (expressing CD45.1) and WASP-/ (CD45.2) BM cells at a 1:3 ratio were injected into lethally irradiated $W A S P^{-/-}$recipient mice. Mice were analyzed 9 to 13 weeks after transplantation. Control mice received WT or WASP ${ }^{-/-} \mathrm{BM}$ alone. (B) Immunohistochemistry of spleen sections from mice receiving WT BM (left panel), WASP ${ }^{-1-}$ BM (middle), and mixed WT: $W A S P^{-/} \mathrm{BM}$ (right). Note that the $\mathrm{MZ}$ architecture in WT:WASP $P^{-1-}$ $\mathrm{BM}$ chimeric mice is fully restored. (C) Splenocytes were labeled with anti-CD21, CD23, and IgM and analyzed by flow cytometry. (Top panel) The percentage of FO and MZ B cells in reconstituted mice is shown for the various conditions as illustrated in panel $\mathrm{B}$. Note that WT:WASP-/- BM chimeric mice have fully restored $\mathrm{MZ}$ B-cell population (right). (Bottom panel) The percentage of WASP-/ CD45.2-expressing FO and MZ B cells is shown. Note the low proportion of WASP ${ }^{-1-} \mathrm{MZ} \mathrm{B}$ cells in the WT:WASP $P^{-1-} \mathrm{BM}$ chimeric mice (right). The data are representative of 2 independent experiments, in which $\mathrm{n}=7$ mice were analyzed (original magnification $\times 10)$.
A

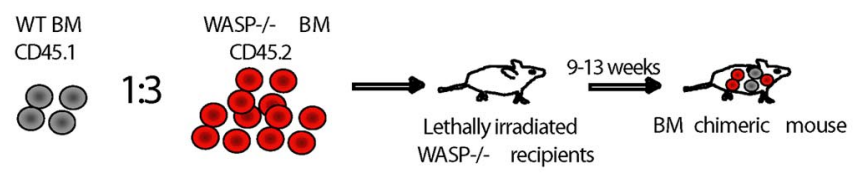

B
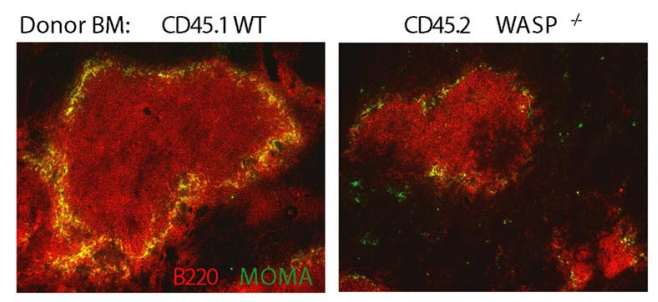

CD45.1/CD45.2(1:3)
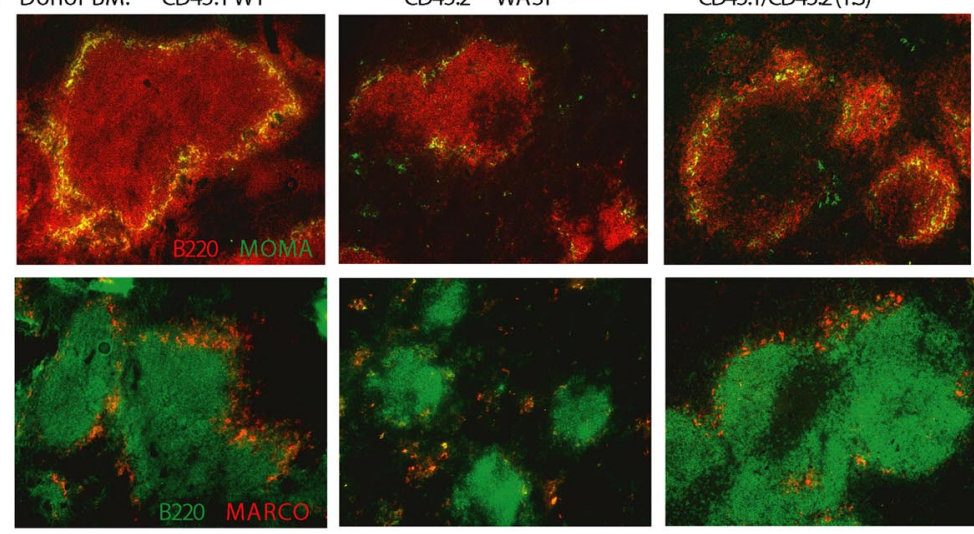

C

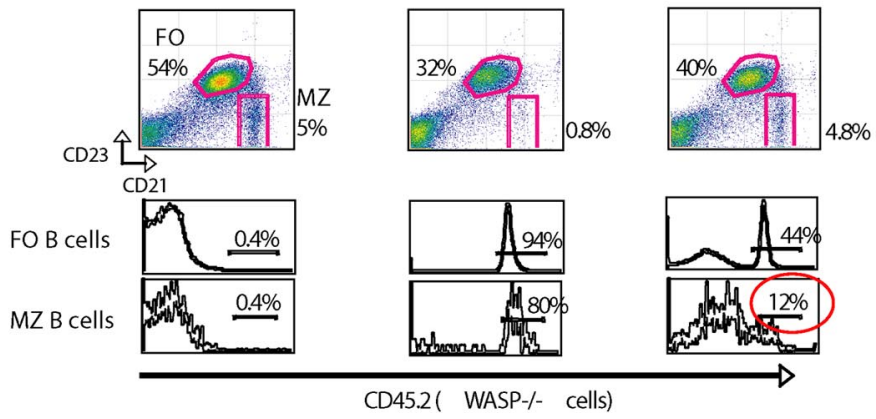

results support the notion that WASP plays a cell-intrinsic role for the presence of MZ B cells independently of MZMs.

\section{Peripheral B-cell development and homeostasis in WASP $^{-/-}$mice}

Our data in $\mathrm{WASP}^{+/-}$mice and in the BM chimeras revealed a strong selection of WASP-expressing cells among T2-MZP B-cell precursors and MZ B cells (Figures $1 \mathrm{~B}$ and $4 \mathrm{~A}$, respectively). In addition, we found a normal number of T1, and T2-FO in WASP $P^{-/-}$ mice, whereas both the proportion and the absolute number of FO $\mathrm{B}$ cells, and especially of T2-MZP and MZ B cells, were reduced in WASP $^{-1-}$ mice compared with WT mice (Figure 4B,C). Together, these results imply that WASP is required for development and/or peripheral homeostasis of B cells. It has been shown that high BCR signaling favors the development of FO B cells, whereas low BCR signaling strength promotes MZ B-cell development. ${ }^{12}$ To evaluate whether lowering the strength of BCR signaling might restore the MZ B-cell compartment in WASP ${ }^{-/-}$mice, we bred mice carrying the btk ${ }^{x i d}$ mutation that have reduced BCR signaling with WASPdeficient mice. ${ }^{23,24}$ We confirmed prior studies ${ }^{24}$ that demonstrated that $\mathrm{btk}^{\text {xid }}$ mice have a normal percentage of MZ B cells (Figure $\mathrm{S} 4)$. We found that the proportion of MZ B cells is partially restored in $W A S P^{-/-} / b^{k} k^{x i d}$ double-mutant mice (Figure S4). To examine the turnover rate of peripheral $\mathrm{B}$ cells in vivo, we performed a BrdU pulse-chase experiment. Mice were fed BrdU in the drinking water for 6 days and followed thereafter for another 6 days (Figure 4D). If WASP deficiency mainly affects development of MZ B cells, we would expect to see less $\mathrm{BrdU}^{+}$cells at this stage, reflecting decreased transition from newly formed B cells. If WASP influences the turnover rate of B cells, we would expect an increased proportion of $\mathrm{BrdU}^{+}$cells. At day 3, we found an increased proportion (Figure 4D) of $\mathrm{BrdU}^{+}$cells in the T2-FO, FO, T2-MZP, and MZ B-cell subsets in WASP ${ }^{-/-}$mice compared with WT mice, suggesting that WASP is required for normal turnover rates of $\mathrm{B}$ cells. Notably, the absolute number of $\mathrm{BrdU}^{+} \mathrm{MZ}$ B cells was similar in WT and $W A S P^{-/-}$mice (data not shown), implying that generation of MZ B cells is unaffected in $W A S P^{-/-}$mice. At day 9, there is a tendency to increased proportion of T2-MZP and MZ $\mathrm{B}$ cells in WASP ${ }^{-/-}$mice compared with WT mice, and this difference becomes significant at day 14. Together, these data indicate that WASP is required for maintenance of peripheral homeostasis of MZ B cells.

\section{WASP-deficient MZ B cells show impaired in vitro migration to S1P}

To evaluate whether the reduced number of $\mathrm{MZ} \mathrm{B}$ cells in $W A S P^{-/-}$ mice resulted from decreased survival, we examined cell death in freshly isolated splenocytes. The frequency of necrotic $\left(7-\mathrm{AAD}^{+}\right)$ and apoptotic $\left(7-\mathrm{AAD}^{-}\right.$annexin $\mathrm{V}^{+}$) cells among $\mathrm{FO}$ and $\mathrm{MZ}$ $\mathrm{B}$ cells was similar in WT and WASP ${ }^{-/-}$mice (Figure 5A). We next examined whether WASP-deficient MZ B cells were impaired in adhesion to ICAM-1 and VCAM-1 and in their migratory response to S1P, all of which are essential for correct MZ positioning. ${ }^{13,14}$ As previously described, ${ }^{13} \mathrm{MZ}$ B cells from WT mice exhibited increased adhesive response to ICAM-1 and VCAM-1 compared with FO B cells (Figure 5B). We found that the adhesive response 
A

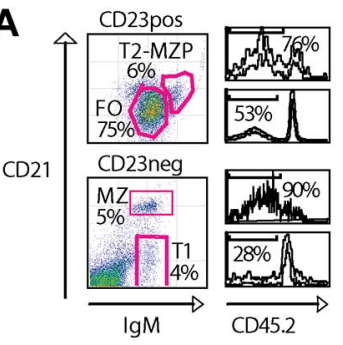

B

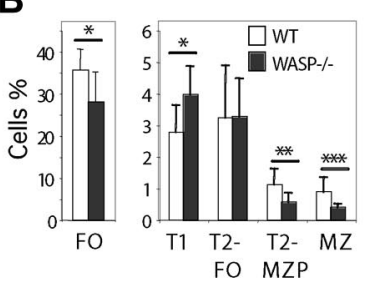

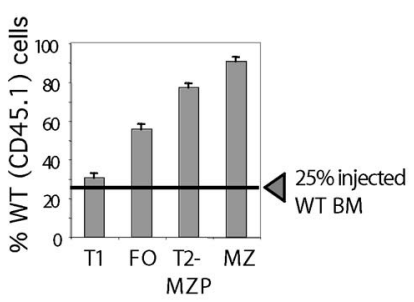

C

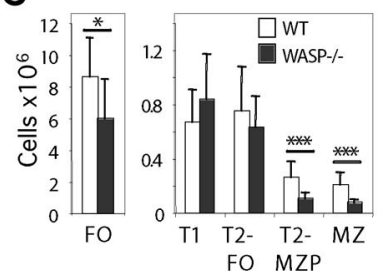

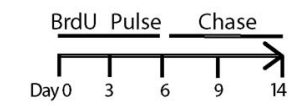

D

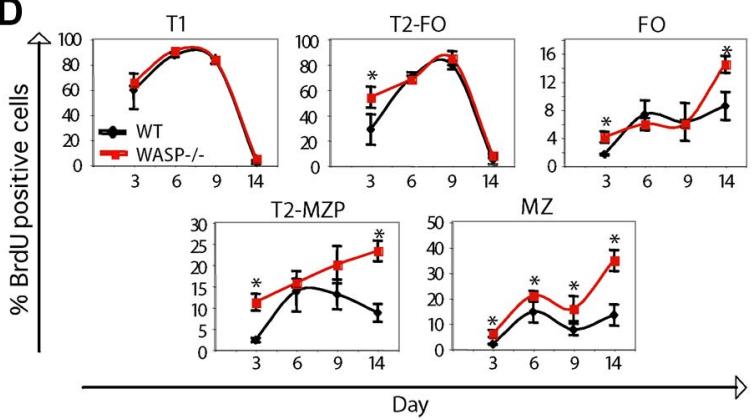

Figure 4. Peripheral B-cell development and homeostasis in WASP-/- mice. (A) Left panel; flow cytometric analysis of WT:WASP $P^{-1-} \mathrm{BM}$ chimeric mice to define the percentage of $\mathrm{WASP}^{+}\left(\mathrm{CD} 45.2^{-}\right)$cells in the T1, FO, T2-MZP, and MZ B-cell populations, using CD21, CD23, and IgM as markers. The middle panel shows the results of one representative experiment, indicating (from top to bottom) the proportion of $\mathrm{WASP}^{+}\left(\mathrm{CD} 45.2^{-}\right)$cells in T2-MZP, FO, MZ B cells, and T1 cells, respectively. The right panel shows the percentage of WASP-expressing $\left(C D 45.1^{+}\right)$ cells in the indicated B-cell populations. The hatched line indicates the $25 \%$ of $\mathrm{WASP}^{+} \mathrm{BM}$ cells that were used for transplantation. The right panel represents data from one of 2 similar experiments with $n=7$ mice. (B) Proportion of T1, T2-FO, FO, T2-MZP, and MZ B cells in WT and WASP ${ }^{-1-}$ mice $(n=10$ mice per group). (C) Absolute numbers of T1, T2-FO, FO, T2-MZP, and MZ B cells in WT and $W A S P^{-1-}$ mice $(\mathrm{n}=10$ mice per group). (D) In vivo BrdU labeling. (Top panel) Mice were fed BrdU in the drinking water for 6 days (pulse) and followed for another 6 days (chase). Proportion of BrdU positive cells was assessed at day 3, 6, 9, and 14. (Bottom panels) The proportion of $\mathrm{BrdU}^{+}$cells of T1, T2-FO, FO, T2-MZP, and MZ $B$ cells as defined by CD21, CD23, CD24, and IgM expression is shown $(n=4$ mice per group). ${ }^{\star} P<.05,{ }^{\star \star} P<.01,{ }^{* \star} P<.005$.

of $\mathrm{WASP}^{-1-} \mathrm{T} 1, \mathrm{FO}, \mathrm{T} 2-\mathrm{MZP}$, and MZ B cells was similar to that of WT cells (Figure 5B). Finally, we used an in vitro chemotaxis assay to examine the chemotactic response of WASP ${ }^{-/-} \mathrm{B}$ cells to S1P. MZ B cells from WT mice showed a dose-dependent migratory response to S1P, as previously described (Figure 5C).$^{14}$ In contrast, $\mathrm{MZ}$ B cells from $\mathrm{WASP}^{-/-}$mice failed to respond to S1P (Figure $5 C)$. Next, we used quantitative real-time PCR to analyze expression of the $\mathrm{S} 1 \mathrm{P}$ receptors, $\mathrm{S}_{1} \mathrm{P}_{1}$ and $\mathrm{S}_{1} \mathrm{P}_{3}$. T2-MZP and MZ B cells from WT mice showed a moderate increase in $\mathrm{S}_{1} \mathrm{P}_{1}$ expression compared with FO B cells, whereas $\mathrm{S}_{1} \mathrm{P}_{3}$ expression was increased 5- to 20 -fold (Figure 5D), as previously described. ${ }^{14} \mathrm{WASP}^{-{ }^{-}}$mice showed reduced expression of $\mathrm{S}_{1} \mathrm{P}_{1}$ in T2-MZP B cells, and of $\mathrm{S}_{1} \mathrm{P}_{3}$ in MZ B cells (Figure 5D).

\section{WASP-deficient mice show reduced specific immune response to TNP-Ficoll}

It was recently shown that positioning of MZ B cells in the MZ is required for capture of blood-borne antigens, such as TNP-Ficoll..$^{25}$ On antigen uptake, MZ B cells shuttle between the MZ and follicle to deliver antigen to follicular DCs, and this shuttling is dependent on CXCL13 and S1P responsiveness. ${ }^{25}$ We reasoned that the reduced number of MZ B cells in WASP-deficient mice together with abolished S1P responsiveness would reduce the immune response to the type 2 T-independent antigen TNP-Ficoll, especially under limiting concentrations of antigen. WT and WASP ${ }^{-\prime-}$ mice were injected intravenously with $2.5 \mu \mathrm{g}$ of TNP-Ficoll when 12 to 14 weeks old. We first examined antigen uptake in the MZ. Consistent with a prior study, ${ }^{25} 30$ minutes after injection, TNPFicoll was detected in the MZ of WT spleens; and after 3 hours, the TNP-Ficoll localized exclusively in B-cell follicles (Figure 6A left panels). In $W A S P^{-/-}$mice, less TNP-Ficoll was found in the MZ after 30 minutes; and after 3 hours, TNP-Ficoll was detected in WASP $P^{-/-}$follicles but to a lesser extent compared with WT follicles. Likewise, we found that $W A S P^{-\prime-} \mathrm{MZ} \mathrm{B}$ cells had reduced uptake of TNP-Ficoll compared with WT MZ B cells (Figure 6A right panel). We next sought to determine the specific antigen response, and serum titers of anti-TNP IgM and IgG3 were measured 7 days after immunization. When immunized with a low dose $(2.5 \mu \mathrm{g})$ of TNP-Ficoll, WASP-deficient mice showed decreased $\mathrm{IgM}$ and $\mathrm{IgG} 3$ response (Figure 6A). A high dose of TNP-Ficoll $(25 \mu \mathrm{g})$ elicited higher IgM and IgG3 responses in both WT and $\mathrm{WASP}^{-/-}$mice (Figure S5A). Although serum IgM and IgG3 levels did not differ between unimmunized WT and WASP ${ }^{-/-}$ mice, ${ }^{16}$ the latter had significantly higher levels of "natural" IgM anti-TNP antibodies (Figure S5B). Likewise, the level of "natural" IgM antiphosphorylcholine antibodies was significantly higher in $W_{A S P^{-/-}}$than in age-matched WT mice (Figure S5C).

\section{Discussion}

Defining the requirement of WASP expression for the selective advantage of specific cell lineages is important for the development of gene therapy and transplantation-based treatment strategies. Using the natural competitive setting of $\mathrm{WASP}^{+/-}$mice, we have shown that WASP is not required for BM HPC maintenance and myeloid cell differentiation, whereas it is important for the development and maturation of T-cell and B-cell lineage cells. Consistent with recent data from our group, ${ }^{21}$ we found no selective advantage for $\mathrm{WASP}^{+}$cells in thymopoiesis during progression to DP cells. WASP conferred some advantage in CD4 and CD8 SP $\mathrm{T}$ cells that was most pronounced in the periphery. Carrier females of WAS show selective inactivation of the mutated X chromosome already in $\mathrm{CD} 34^{+}$cells ${ }^{26}$ thus preventing analysis of the role of WASP along hematopoietic development in this setting. Our data in $W_{A S P^{+/}}$mice are consistent with the demonstration that genetic reversion confers advantage mostly to mature $\mathrm{T}$ cells in patients with $\mathrm{WAS}^{27,28}$ and with data showing selective accumulation of WASP $^{+} \mathrm{T}$ cells after introduction of the WASP gene into HPCs of WASP $P^{-/-}$mice. ${ }^{19,29}$ The relative role of WASP in T-cell development may vary between human and mice because of speciesspecific differences in the level of N-WASP expression. In particular, mice devoid of both N-WASP and WASP in T cells had a severe block in thymocyte development. ${ }^{21}$

The most pronounced selective advantage for WASP-expressing $\mathrm{T}$ cells was found within Tregs and NKT cells. Several recent 
A

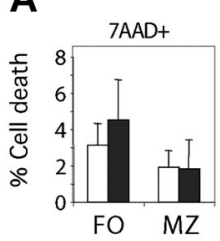

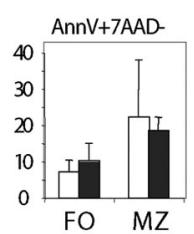

B

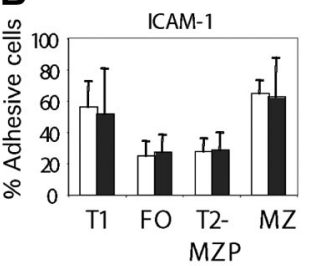

D
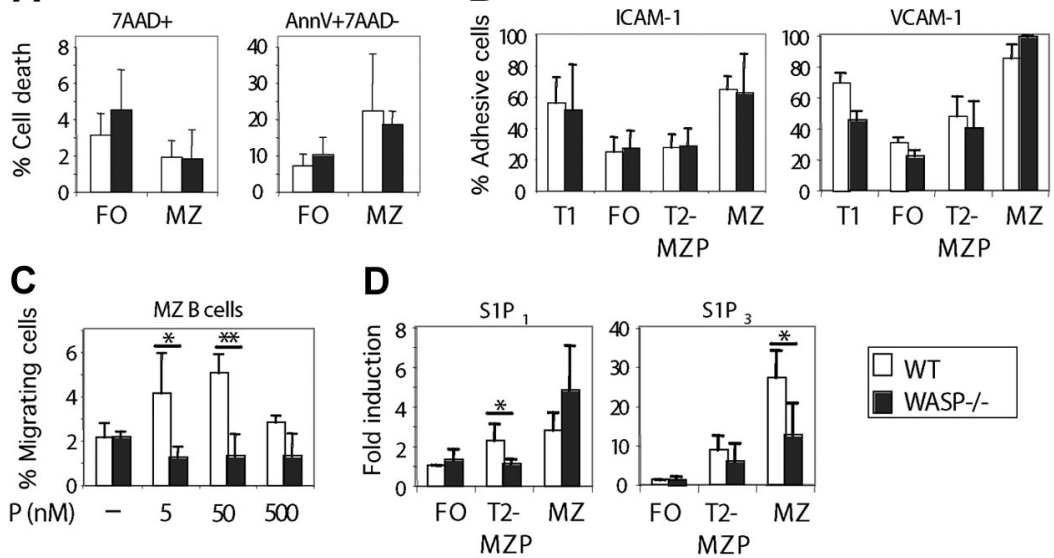

Figure 5. WASP-deficient MZ B cells show impaired in vitro migration to S1P. (A) Flow cytometric analysis of cell death in freshly isolated FO and MZ B cells, identified based on CD21 and CD23 expression. Necrotic cells were defined as 7-AAD ${ }^{+}$(left panel) and apoptotic cells as 7-AAD ${ }^{-}$annexin $V^{+}$(right). $N=6$ mice per group. (B) Adhesive response of T1, FO, T2-MZP, and MZ B cells to ICAM-1 (left panel) and VCAM-1 (right). Splenocytes were allowed to adhere to tissue culture plates coated with indicated ligands for 2 hours. Adherent cells were released by ethylenediaminetetraacetic acid, stained for CD21, CD23, and IgM to define B-cell subsets, and enumerated by flow cytometry. The percentage of adhesive cells as a fraction of total input cells is shown as mean values $( \pm$ SD). This experiment is representative of 2 similar ones with $n=3$ mice per group. (C) Migratory response of MZ B cells to S1P was determined by an in vitro chemotaxis assay. The percentage of cells that migrated after 3 hours in the chemotaxis assay was determined and represents the mean value ( \pm SD) of $n=3$ mice per group. This experiment represents 2 similar experiments. (D) Real-time PCR analysis of $S 1 P_{1}$, and $S 1 P_{3}$ in FO, T2-MZP, and MZ B cells. B cells from 3 mice per group were pooled and cell-sorted based on CD21, CD23, and IgM expression. Samples were run in triplicate, and the target mRNA was normalized to HPRT mRNA. The mRNA content of test sample in WT FO B cells was defined as 1 arbitrary unit. Mean value $( \pm \mathrm{SD})$ of triplicates is shown, and the data are representative of 3 similar experiments. ${ }^{*} P<.05,{ }^{\star \star} P<.01$.

studies have demonstrated a critical role for WASP in Treg function. ${ }^{18,30-32}$ We have previously demonstrated a reduced number of Tregs in the thymus of WASP-deficient animals. ${ }^{31}$ We now show that expression of WASP confers a strong selective advantage to Tregs both in the thymus and in the spleen of $W A S P^{+/-}$mice. These data differ in part from a previous observation by Humblet-

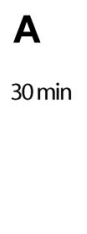

$3 \mathrm{hrs}$

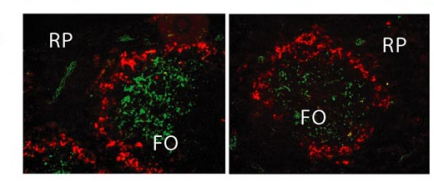

B

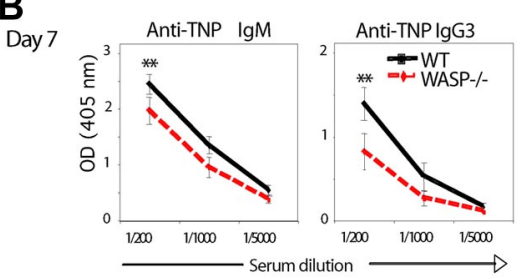

Figure 6. WASP-deficient mice show reduced specific immune response to TNP-Ficoll. WT and WASP ${ }^{-/-}$mice when 12 to 14 weeks old were injected intravenously with $2.5 \mu \mathrm{g}$ of TNP-Ficoll. (A) Uptake of TNP-Ficoll in spleens 30 minutes and 3 hours after injection. (Left panel) Spleen sections were labeled to detect TNP-Ficoll and MOMA ${ }^{+}$metallophilic macrophages to define the MZ. Note the reduced TNP staining in the $M Z$ at 30 minutes (top panels) and in the follicles at 3 hours (bottom panels) in WASP ${ }^{-1-}$ mice compared with WT mice (original magnification $\times 20$ ). (Right panels) $M Z B$ cells were labeled with anti-TNP and analyzed by flow cytometry $(n=5)$. (B) Anti-TNP IgM and IgG3 antibody titers were determined at day 7 after immunization by enzyme-linked immunosorbent assay. Each group represents mean values $( \pm S D$ ) from $n=5$ mice, which were corrected for background binding. FO indicates B-cell follicle; MZ, marginal zone; non-B, lymphocytes negative for CD21 and IgM; RP, red pulp. ${ }^{\star} P<.05,{ }^{* \star} P<.01$.
Baron et al that demonstrated selective advantage for WASPexpressing Tregs in the periphery, but not in the thymus of $W_{A S P^{+/-}}$mice $^{18}$ and may reflect use of different murine strains. We found strong selective advantage for WASP-expressing NKT cells both in the thymus and in the periphery; in addition, $\mathrm{WASP}^{-/-}$mice had a reduced number of NKT cells both in the thymus and in the periphery. Natural Tregs and NKT cells are detected in WASPdeficient mice indicating that lack of WASP does not prevent development of these cell types. However, WASP may play a role in the maintenance and/or fitness of these cell lineages as we observed a striking advantage for WASP-expressing nTregs and NKT cells in $\mathrm{WASP}^{+/-}$mice. Because NKT cells have important immunomodulatory activity, ${ }^{33}$ numerical or functional defects of such cells might contribute to the immunopathology of WAS patients and $\mathrm{WASP}^{-1-}$ mice.

Because WASP-deficient myeloid cells have been demonstrated to have several functional defects both in vitro and in vivo, ${ }^{34-39}$ restoration of WASP expression in the myeloid compartment may be required for successful treatment of WAS patients. Two recent studies show that WASP gene transfer into HPC from WAS patients reconstitutes the actin cytoskeleton in myeloid progeny cells differentiated in vitro. ${ }^{5,40}$ Moreover, a modest advantage of WASPexpressing neutrophils and myeloid cells was seen using BM competitive repopulation experiments. ${ }^{29}$ However, we found little or no evidence of selective advantage for WASP expressing myeloid cells in $\mathrm{WASP}^{+/-}$mice and on in vitro culture with M-CSF or GM-CSF. Overall, the selection for WASP-expressing myeloid cells appears less robust than in other lineages. This may have significant implications for the development of gene therapy protocols for WAS, although in humans expression of WASP appears to confer a significant advantage already in HPCs, as shown in carrier females. ${ }^{26}$

Thrombocytopenia is a major complication in WAS and frequently the cause for fatal outcome of the disease. ${ }^{41,42}$ Lack of donor myeloid engraftment is associated with increased risk of persistent thrombocytopenia after HSCT. ${ }^{3,43}$ Our data in $\mathrm{WASP}^{+/-}$ mice have shown that, despite lack of selective advantage in the 
myeloid compartment, a moderate excess of $\mathrm{WASP}^{+}$platelets was present in the circulation. Although it remains to be seen whether such increase reflects advantage in the number and/or differentiation of WASP-expressing megakaryocytes or an increased peripheral consumption of WASP-negative platelets, these data represent an encouraging result in view of the potential use of gene therapy in WAS.

The role of WASP in B-cell development, maturation, and function is controversial. Patients with WAS have a reduced number of circulating B lymphocytes. ${ }^{44}$ On the other hand, analysis of WAS patients in which somatic reversion occurred in a common lymphoid progenitor failed to demonstrate significant advantage for WASP-expressing B cells, suggesting that expression of WASP does not play a critical role in B-cell differentiation. ${ }^{45}$ Although our data confirm that WASP does not play an important role in early stages of B-cell development in the BM, we found that BM mature recirculating $\mathrm{B}$ cells as well as follicular and $\mathrm{MZ} \mathrm{B}$ cells in the spleen of $\mathrm{WASP}^{+/-}$mice were comprised mostly of $\mathrm{WASP}^{+}$cells, suggesting that WASP is involved in peripheral B-cell maturation and/or homeostasis. Consistent with our previous findings that WASP may be required for optimal GC reaction, ${ }^{8}$ we show that the proportion of $\mathrm{WASP}^{+}$cells was higher among $\mathrm{PNA}^{+}$than among $\mathrm{PNA}^{-} \mathrm{B}$ cells from the Peyer patches of unimmunized $\mathrm{WASP}^{+/-}$ mice and from the spleen of immunized mice.

We previously reported that WASP deficiency in humans and mice is associated with severe abnormalities of the MZ and a marked reduction of MZ B cells. ${ }^{8,9}$ We now provide several independent lines of evidence that WASP is critically involved in MZ B-cell biology. MZ B cells from $\mathrm{WASP}^{+/-}$mice are almost entirely composed of $\mathrm{WASP}^{+}$cells. This selective advantage for WASP-expressing cells is already apparent in T2-MZP cells. Moreover, we have found that the proportion of T2-MZP and of MZ B cells is significantly reduced in $W A S P^{-/-}$mice. Differentiation of MZ B cells has been shown to be dependent on BCRmediated signaling, such that $\mathrm{MZ} B$ cells require less signaling through the BCR for development. ${ }^{12}$ We found that lowering BCR signaling in $W A S P^{-/ y} / B T K^{\mathrm{xid} / \mathrm{y}}$ mice partially rescued differentiation of MZ B cells compared with $W A S P^{-/-}$mice, indicating that aberrant BCR-mediated signaling may contribute, at least in part, to the reduced number of $\mathrm{MZ} \mathrm{B}$ cells in $\mathrm{WASP}^{-1-}$ mice. Furthermore, we found increased proliferation in $\mathrm{MZ} B$ cells from $W_{A S P^{-/-}}$mice (as shown by analysis of BrdU incorporation) and similar absolute number of newly generated $\mathrm{MZ} B$ cells in $W A S P^{-/-}$and WT mice. In the absence of clear abnormalities in apoptosis, these data suggest that the reduced number of $\mathrm{MZ}$ $\mathrm{B}$ cells in WASP-deficient mice might result from abnormalities of homeostasis and/or retention.

$\mathrm{S} 1 \mathrm{P}$ is critically involved in positioning of MZ B cells. ${ }^{25} \mathrm{We}$ have shown that WASP-deficient MZ B cells have reduced migration in response to $\mathrm{S} 1 \mathrm{P}$. We had previously shown that WASP-deficient $\mathrm{B}$ lymphocytes are impaired in response to CXCL13. ${ }^{8} \mathrm{MZ} \mathrm{B}$ cells shuttle between the MZ- and B-cell follicles in response to $\mathrm{S} 1 \mathrm{P}$ and CXCL13, respectively. ${ }^{25}$ This shuttling is important in delivering blood-borne antigens captured in the MZ to follicular DCs. In this regard, it is possible that the reduced responsiveness of WASP-deficient MZ B cells to S1P and to CXCL13 contributes to the impaired antibody response to Tindependent antigens.

Organization of the MZ is dependent both on MZ B cells and on a MZM. Transient depletion of MZMs with clodronate liposome has been shown to result in a severe reduction of MZ B cells. ${ }^{15} \mathrm{On}$ the other hand, progressive disappearance of MZ B cells is associated with simultaneous decline in the number of MZMs, resulting in disruption of the $\mathrm{MZ}$ architecture. ${ }^{46}$ To define whether loss of MZ B cells and MZMs in WASP ${ }^{-1-}$ mice are related events, we performed $\mathrm{BM}$ chimeric repopulation experiments using cells from $W_{A S P^{+/+}}$and $W A S P^{-/-}$mice. Our data have shown that, even when the MZM compartment is restored, differentiation of MZ $\mathrm{B}$ cells is strictly dependent on WASP, indicating a B-cell intrinsic role of WASP expression in MZ B-cell development.

The severe deficiency of MARCO $^{+}$MZMs in WASP-deficient $^{-}$ mice might play an important role in the susceptibility of WAS patients to invasive infections by encapsulated pathogens. ${ }^{41} \mathrm{We}$ have found that the severe reduction of MZMs in WASP ${ }^{-/-}$mice results in aberrant uptake of $S$ aureus. Moreover, MARCO and the scavenger receptor SR-A have the capacity to bind apoptotic cells, a major source of autoantigens. ${ }^{47}$ Mice double-deficient in the expression of MARCO and SR-A develop anti-DNA antibodies at high titers, both spontaneously and after injection with apoptotic cells, indicating that clearance of apoptotic cells is needed for correct regulation of B-cell tolerance. Peritoneal macrophages from WASP-deficient mice show decreased uptake of apoptotic cells ${ }^{48}$ and WASP-deficient mice produce anti-dsDNA antibodies. ${ }^{18}$ We have now shown that $W_{A S P^{-/}}$mice have increased levels of anti-TNP and antiphosphorylcholine "natural" IgM, which have been associated with low-affinity and potentially autoreactive IgM responses. 49

In conclusion, our data show that WASP controls lymphoid maturation and homeostasis and plays a critical role for WASP in MZ development and organization. These observations provide novel insight into the immunodeficiency of WAS and may guide therapeutic approaches dependent on gene transfer.

\section{Acknowledgments}

The authors thank Svend Rietdijk and Cox Terhorst (Harvard Medical School, Boston, MA) for CD1d tetramers, David Dombkowski (Harvard Medical School) for cell sorting and LSR II analysis, and John Manis, Eileen Remold O'Donnell, Deanna Nguyen (Harvard Medical School), Silvia Giliani (University of Brescia, Brescia, Italy), and Eva Severinson (Stockholm University, Stockholm, Sweden) for helpful discussions.

This work was supported by a postdoctoral fellowship from the Swedish Society for Medical Research (L.W.) and National Institutes of Health grants HL59561 and AI50950 (S.B.S.) and grant P01HL059561-A11 (S.B.S. and L.S.N.).

\section{Authorship}

Contribution: L.W., M.A.d.I.F., M.C.I.K., S.B.S., and L.D.N. designed research; L.W., M.A.d.1.F., F.W., and M.C.I.K. performed research; H.D.O. contributed new reagents/analytic tools; L.W., M.A.d.l.F., F.W., M.C.I.K., S.B.S., and L.D.N. analyzed data; and L.W., M.A.d.1.F., S.B.S., and L.D.N. wrote the paper.

Conflict-of-interest disclosure: The authors declare no competing financial interests.

Correspondence: Scott B. Snapper, Massachusetts General Hospital, Jackson 825c, 55 Fruit Street, Boston, MA 02114; e-mail: ssnapper@hms.harvard.edu; or Luigi D. Notarangelo, Children's Hospital, 1 Blackfan Circle, Boston, MA 02115; e-mail: Luigi.Notarangelo@childrens.harvard.edu. 


\section{References}

1. Notarangelo LD, Miao $\mathrm{CH}$, Ochs HD. WiskottAldrich syndrome. Curr Opin Hematol. 2008;15: 30-36.

2. Filipovich AH, Stone JV, Tomany SC, et al. Impact of donor type on outcome of bone marrow transplantation for Wiskott-Aldrich syndrome: collaborative study of the International Bone Marrow Transplant Registry and the National Marrow Donor Program. Blood. 2001;97:1598-1603.

3. Pai SY, DeMartiis D, Forino C, et al. Stem cell transplantation for the Wiskott-Aldrich syndrome: a single-center experience confirms efficacy of matched unrelated donor transplantation. Bone Marrow Transplant. 2006;38:671-679.

4. Ozsahin $\mathrm{H}$, Cavazzana-Calvo $\mathrm{M}$, Notarangelo $\mathrm{LD}$, et al. Long-term outcome following hematopoietic stem-cell transplantation in Wiskott-Aldrich syndrome: collaborative study of the European Society for Immunodeficiencies and European Group for Blood and Marrow Transplantation. Blood. 2008;111:439-445.

5. Dewey RA, Avedillo Diez I, Ballmaier M, et al. Retroviral WASP gene transfer into human hematopoietic stem cells reconstitutes the actin cytoskeleton in myeloid progeny cells differentiated in vitro. Exp Hematol. 2006;34:1161-1169.

6. Galy A, Roncarolo MG, Thrasher AJ. Development of lentiviral gene therapy for Wiskott Aldrich syndrome. Expert Opin Biol Ther. 2008;8:181 190.

7. Mebius RE, Kraal G. Structure and function of the spleen. Nat Rev Immunol. 2005;5:606-616.

8. Westerberg L, Larsson M, Hardy SJ, Fernandez C, Thrasher AJ, Severinson E. Wiskott-Aldrich syndrome protein deficiency leads to reduced B-cell adhesion, migration, and homing, and delayed humoral immune response. Blood. 2005; 105:1144-1152.

9. Vermi W, Blanzuoli L, Kraus MD, et al. The spleen in the Wiskott-Aldrich syndrome: histopathologic abnormalities of the white pulp correlate with the clinical phenotype of the disease. Am J Surg Pathol. 1999;23:182-191.

10. Lopes-Carvalho T, Kearney JF. Development and selection of marginal zone B cells. Immunol Rev. 2004;197:192-205.

11. Saito T, Chiba S, Ichikawa M, et al. Notch2 is preferentially expressed in mature $B$ cells and indispensable for marginal zone $\mathrm{B}$ lineage development. Immunity. 2003;18:675-685.

12. Pillai S, Cariappa A, Moran ST. Marginal zone B cells. Annu Rev Immunol. 2005;23:161-196.

13. Lu TT, Cyster JG. Integrin-mediated long-term B cell retention in the splenic marginal zone. Science. 2002;297:409-412.

14. Cinamon G, Matloubian M, Lesneski MJ, et al. Sphingosine 1-phosphate receptor 1 promotes $B$ cell localization in the splenic marginal zone. Nat mmunol. 2004:5:713-720.

15. Karlsson MC, Guinamard R, Bolland S, Sankala M, Steinman RM, Ravetch JV. Macrophages control the retention and trafficking of $B$ lymphocytes in the splenic marginal zone. J Exp Med. 2003; 198:333-340.

16. Snapper SB, Rosen FS, Mizoguchi E, et al. Wiskott-Aldrich syndrome protein-deficient mice reveal a role for WASP in T but not B cell activation. Immunity. 1998;9:81-91.

17. Zhu Q, Watanabe C, Liu T, et al. Wiskott-Aldrich syndrome/X-linked thrombocytopenia: WASP gene mutations, protein expression, and phenotype. Blood. 1997;90:2680-2689.

18. Humblet-Baron S, Sather B, Anover S, et al. Wiskott-Aldrich syndrome protein is required for regulatory T cell homeostasis. J Clin Invest. 2007 117:407-418.

19. Klein C, Nguyen D, Liu CH, et al. Gene therapy for Wiskott-Aldrich syndrome: rescue of T-cell signaling and amelioration of colitis upon transplantation of retrovirally transduced hematopoietic stem cells in mice. Blood. 2003;101:21592166.

20. Lacout C, Haddad E, Sabri S, et al. A defect in hematopoietic stem cell migration explains the nonrandom X-chromosome inactivation in carriers of Wiskott-Aldrich syndrome. Blood. 2003; 102:1282-1289.

21. Cotta-de-Almeida V, Westerberg $\mathrm{L}$, Maillard $\mathrm{MH}$, et al. Wiskott Aldrich syndrome protein (WASP) and N-WASP are critical for T cell development. Proc Natl Acad Sci U S A. 2007;104:1542415429.

22. Hardy RR, Hayakawa K. B-cell development pathways. Annu Rev Immunol. 2001;19:595-621.

23. Rawlings DJ, Saffran DC, Tsukada S, et al. Mutation of unique region of Bruton's tyrosine kinase in immunodeficient XID mice. Science. 1993;261: 358-361.

24. Khan WN, Alt FW, Gerstein RM, et al. Defective B-cell development and function in Btk-deficient mice. Immunity. 1995;3:283-299.

25. Cinamon G, Zachariah MA, Lam OM, Foss FW Jr, Cyster JG. Follicular shuttling of marginal zone $B$ cells facilitates antigen transport. Nat Immunol. 2008;9:54-62.

26. Wengler G, Gorlin JB, Williamson JM, Rosen FS Bing $\mathrm{DH}$. Nonrandom inactivation of the $\mathrm{X}$ chromosome in early lineage hematopoietic cells in carriers of Wiskott-Aldrich syndrome. Blood. 1995:85:2471-2477.

27. Stewart DM, Candotti F, Nelson DL. The phenom enon of spontaneous genetic reversions in the Wiskott-Aldrich syndrome: a report of the workshop of the ESID Genetics Working Party at the XIlth Meeting of the European Society for Immunodeficiencies (ESID). Budapest, Hungary October 4-7, 2006. J Clin Immunol. 2007;27:634-639.

28. Wada T, Schurman SH, Jagadeesh GJ, Garabedian EK, Nelson DL, Candotti F. Multiple patients with revertant mosaicism in a single Wiskott-Aldrich syndrome family. Blood. 2004; 104:1270-1272.

29. Strom TS, Turner SJ, Andreansky S, et al. Defects in T-cell-mediated immunity to influenza virus in murine Wiskott-Aldrich syndrome are corrected by oncoretroviral vector-mediated gene transfer into repopulating hematopoietic cells. Blood. 2003;102:3108-3116.

30. Adriani M, Aoki J, Horai R, et al. Impaired in vitro regulatory $T$ cell function associated with WiskottAldrich syndrome. Clin Immunol. 2007:124:41-48.

31. Maillard MH, Cotta-de-Almeida V, Takeshima F, et al. The Wiskott-Aldrich syndrome protein is required for the function of CD4(+)CD25(+)Foxp3(+) regulatory T cells. J Exp Med. 2007;204:381-391.

32. Marangoni F, Trifari S, Scaramuzza S, et al. WASP regulates suppressor activity of human and murine CD4(+)CD25(+)FOXP3(+) natural regulatory T cells. J Exp Med. 2007;204:369-380.
33. Bendelac A, Savage PB, Teyton L. The biology of NKT cells. Annu Rev Immunol. 2007;25:297-336.

34. Badolato R, Sozzani S, Malacarne F, et al. Monocytes from Wiskott-Aldrich patients display reduced chemotaxis and lack of cell polarization in response to monocyte chemoattractant protein-1 and formyl-methionyl-leucyl-phenylalanine. J Immunol. 1998;161:1026-1033.

35. Bouma G, Burns S, Thrasher AJ. Impaired T-cell priming in vivo resulting from dysfunction of WASp-deficient dendritic cells. Blood. 2007;110: 4278-4284.

36. Burns S, Cory GO, Vainchenker W, Thrasher AJ. Mechanisms of WASp-mediated hematologic and immunologic disease. Blood. 2004;104:34543462.

37. de Noronha S, Hardy S, Sinclair J, et al. Impaired dendritic-cell homing in vivo in the absence of Wiskott-Aldrich syndrome protein. Blood. 2005; 105:1590-1597.

38. Snapper SB, Meelu P, Nguyen D, et al. WASP deficiency leads to global defects of directed leukocyte migration in vitro and in vivo. J Leukoc Biol. 2005; 77:993-998.

39. Zicha D, Allen WE, Brickell PM, et al. Chemotaxis of macrophages is abolished in the Wiskott-Aldrich syndrome. Br J Haematol. 1998;101:659665.

40. Charrier S, Dupre L, Scaramuzza S, et al. Lentiviral vectors targeting WASp expression to hematopoietic cells, efficiently transduce and correct cells from WAS patients. Gene Ther. 2007;14: 415-428.

41. Sullivan KE, Mullen CA, Blaese RM, Winkelstein JA. A multiinstitutional survey of the Wiskott-Aldrich syndrome. J Pediatr. 1994;125:876-885.

42. Wada T, Jagadeesh GJ, Nelson DL, Candotti F. Retrovirus-mediated WASP gene transfer corrects Wiskott-Aldrich syndrome T-cell dysfunction. Hum Gene Ther. 2002;13:1039-1046.

43. Yamaguchi K, Ariga T, Yamada M, et al. Mixed chimera status of 12 patients with Wiskott-Aldrich syndrome (WAS) after hematopoietic stem cell transplantation: evaluation by flow cytometric analysis of intracellular WAS protein expression. Blood. 2002;100:1208-1214.

44. Park JY, Shcherbina A, Rosen FS, Prodeus AP, Remold-O'Donnell E. Phenotypic perturbation of $B$ cells in the Wiskott-Aldrich syndrome. Clin Exp Immunol. 2005;139:297-305.

45. Konno A, Wada T, Schurman SH, et al. Differential contribution of Wiskott-Aldrich syndrome protein to selective advantage in T- and B-cell lineages. Blood. 2004;103:676-678.

46. Nolte MA, Arens R, Kraus M, et al. B cells are crucial for both development and maintenance of the splenic marginal zone. J Immunol. 2004;172:3620 3627.

47. Wermeling F, Chen Y, Pikkarainen T, et al. Class A scavenger receptors regulate tolerance against apoptotic cells, and autoantibodies against these receptors are predictive of systemic lupus. J Exp Med. 2007;204:2259-2265.

48. Leverrier Y, Lorenzi R, Blundell MP, et al. Cutting edge: the Wiskott-Aldrich syndrome protein is required for efficient phagocytosis of apoptotic cells. J Immunol. 2001;166:4831-4834.

49. Zhang M, Carroll MC. Natural IgM-mediated innate autoimmunity: a new target for early intervention of ischemia-reperfusion injury. Expert Opin Biol Ther. 2007;7:1575-1582. 